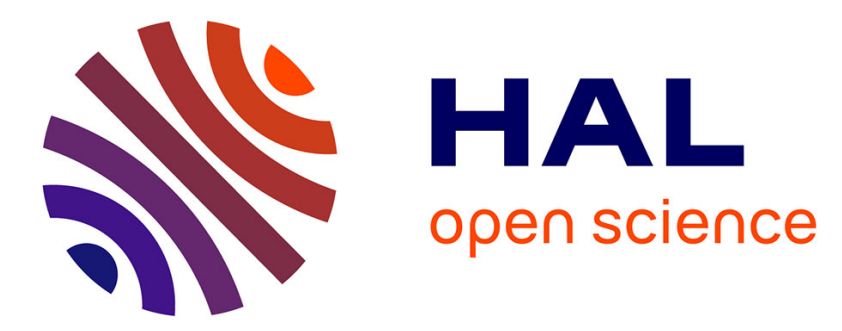

\title{
Organometallic synthesis of $\mathrm{ZnO}$ nanoparticles for gas sensing: Towards selectivity through nanoparticles morphology
}

Andrey Ryzhikov, Justyna Jońca, Myrtil L. Kahn, Katia Fajerwerg, Bruno Chaudret, Audrey Chapelle, Philippe Menini, C. H. Shim, A. Gaudon, P. Fau

\section{To cite this version:}

Andrey Ryzhikov, Justyna Jońca, Myrtil L. Kahn, Katia Fajerwerg, Bruno Chaudret, et al.. Organometallic synthesis of $\mathrm{ZnO}$ nanoparticles for gas sensing: Towards selectivity through nanoparticles morphology. Journal of Nanoparticle Research, 2015, 17 (7), pp.280/1-10. 10.1007/s11051-0153086-2 . hal-02020351v2

\section{HAL Id: hal-02020351 \\ https://hal.science/hal-02020351v2}

Submitted on 4 Apr 2019

HAL is a multi-disciplinary open access archive for the deposit and dissemination of scientific research documents, whether they are published or not. The documents may come from teaching and research institutions in France or abroad, or from public or private research centers.
L'archive ouverte pluridisciplinaire HAL, est destinée au dépôt et à la diffusion de documents scientifiques de niveau recherche, publiés ou non, émanant des établissements d'enseignement et de recherche français ou étrangers, des laboratoires publics ou privés. 


\title{
Organometallic Synthesis of ZnO Nanoparticles for Gas Sensing: Towards Selectivity Through Nanoparticles Morphology.
}

\author{
Andrey Ryzhikov ${ }^{1}$, Justyna Jońca ${ }^{1}$, Myrtil Kahn ${ }^{1}$, Katia Fajerwerg ${ }^{1,2}$, Bruno Chaudret ${ }^{3}$, \\ Audrey Chapelle ${ }^{4}$, Philippe Ménini ${ }^{2,4}$, Chang Hyun Shim ${ }^{4,5}$, Alain Gaudon ${ }^{5}$, Pierre Fau 1,2 * \\ 1 Laboratoire de Chimie de Coordination (LCC), CNRS, 205 route de Narbonne, 31077 Toulouse \\ Cedex 4, France \\ 2 Université Toulouse III, Paul Sabatier, 118 route de Narbonne, 31062 Toulouse Cedex 9, France \\ 3 Laboratoire de Physique et de Chimie de Nano-objets (LPCNO), INSA, UPS, CNRS, 135 avenue \\ de Rangueil, 31077 Toulouse, Cedex 4, France \\ 4 Laboratoire d'Analyse et d'Architecture des Systèmes (LAAS), CNRS, 5 avenue du Colonel Roche, \\ 31400 Toulouse, France \\ 5 Alpha MOS, 20 avenue Didier Daurat, 31400 Toulouse, France \\ * Author to whom correspondence should be addressed; \\ E-Mail: pierre.fau@lcc-toulouse.fr; Tel.: +33 0561333181; Fax: +33 0561553003
}

\begin{abstract}
ZnO}$ nanoparticles with different morphology such as nanorods (NR), isotropic nanoparticles (NP) and cloud-like (CL) structures have been synthesized by an organometallic route. The prepared $\mathrm{ZnO}$ nanostructures have been deposited on miniaturized silicon gas sensor substrates by an ink-jet method, and their responses to $\mathrm{CO}, \mathrm{C}_{3} \mathrm{H}_{8}$ and $\mathrm{NH}_{3}$ gases have been studied at different operating temperatures $\left(340-500^{\circ} \mathrm{C}\right)$ and relative humidity of $50 \%$. It is noteworthy that the morphology of the nanostructure of the sensitive layer is maintained after thermal treatment. The morphology of $\mathrm{ZnO}$ nanoparticles significantly influences the sensors response level and their selectivity properties to reducing gases. Among the three different $\mathrm{ZnO}$ types, sensors prepared with NR show the highest response to both $\mathrm{CO}$ and $\mathrm{C}_{3} \mathrm{H}_{8}$. Sensors made of isotropic NP and CL structures show a lower but similar to each other response to $\mathrm{CO}$. From all investigated nanostructures, sensors made of CL structures show the weakest response to $\mathrm{C}_{3} \mathrm{H}_{8}$. With $\mathrm{NH}_{3}$ gas, no effect of the morphology of the $\mathrm{ZnO}$ sensitive layer has been evidenced. These different responses highlight the important role of the nanostructure of the $\mathrm{ZnO}$ sensitive layer and the nature of the target gas on the detection properties of the sensors.
\end{abstract}

Keywords: gas sensor, zinc oxide, morphology influence, nanoparticles, nanorods, crystalline faces, selectivity.

\section{Introduction}

Metal oxide semiconductors (MOS) such as $\mathrm{SnO}_{2}, \mathrm{ZnO}, \mathrm{WO}_{3}$ or $\mathrm{In}_{2} \mathrm{O}_{3}$ are widely studied as sensing materials for resistive type gas sensors due to their high sensitivity, chemical stability and good flexibility in fabrication processes (Simon et al., 2001). The main disadvantage of such sensors is their lack of selectivity since usually all reducing or oxidizing gases react with the metal oxide surface giving rise to a transduction signal. To overcome this drawback, the selectivity to target molecules can be greatly improved by i) the addition of doping elements (Yamazoe et al., 1983), ii) the use of different 
heating temperatures, various operating modes of the sensors (Heilig et al., 1997), or iii) the introduction of catalytic filters (Ryzhikov et al, 2005). An enhancement of the sensor selectivity can be also achieved by the combination of different sensing materials and the fine tuning of the operating parameters (heating conditions, temperature cycling ...) in multi-sensor devices (Weimar and Goepel, 1998). The morphology control of nanosized MOS can also be envisaged to improve the selectivity towards various gases (. Indeed, it is well established that the surface reactivity of MOS varies depending on their crystalline faces (Cobden et al., 1999). Many studies report that the catalytic activity of the metal oxide nanoparticles can greatly depend on their morphology and the exposed crystalline faces (Chand Singh et al., 2008; Liao et al., 2011; Liu et al., 2011; Wang et al., 2011; Rai et al., 2013; Zhao at al., 2014).

However, the morphology effect on gas sensing properties of semiconducting metal oxide obtained from the same synthetic procedure is rarely described in the literature. The modification of the exposed crystalline faces of $\mathrm{ZnSnO}_{3}$ polyhedral microcrystals have been reported to considerably modify their response to $\mathrm{H}_{2} \mathrm{~S}, \mathrm{HCHO}$ and $\mathrm{C}_{2} \mathrm{H}_{5} \mathrm{OH}$ but without significant change of selectivity (Geng et al., 2008). $\mathrm{SnO}_{2}, \mathrm{ZnO}$ and $\mathrm{In}_{2} \mathrm{O}_{3}$ nanostructures have been reported to present different response level to $\mathrm{NH}_{3}$ gas depending on their shape (i.e. nanorods or nanoparticles) (Rout et al., 2007). Gupta and co-workers have shown that $\mathrm{ZnO}$ nanotetrapods and nanowires (grown by high temperature evaporation of $\mathrm{Zn}$ ) possess higher response to $\mathrm{H}_{2} \mathrm{~S}$ and $\mathrm{NO}$ than polycrystalline $\mathrm{ZnO}$ films and that the response is mainly determined by intergrain barriers (Gupta et al., 2010). $\mathrm{ZnO}$ nanorods with higher response to $\mathrm{NO}_{2}$ than $\mathrm{ZnO}$ nanosheets have recently been reported (Bai et al., 2011). Tungsten oxide nanoplates with higher sensitivity to acetone than $\mathrm{WO}_{3}$ isotropic nanoparticles have also been described (Chen et al., 2011). The sensing properties of $\mathrm{WO}_{3}$ nanowires or thin films towards $\mathrm{CH}_{3} \mathrm{OH}, \mathrm{CO}$ and $\mathrm{NO}_{2}$ gases are different enough to allow their use in selective multisensor systems (Benkstein et al., 2009). However, $\mathrm{SnO}_{2}$ nanoparticles with different morphologies have been reported without significant influence on the sensor selectivity (Le et al., 2010; Shaalan et al., 2011, Yu et al., 2011). Importantly, the changes of the sensor response are, in most of the cases, correlated with the specific surface area rather than with the morphology of the nanostructures (Wu et al., 2006; Xu et al., 2008; Zhang et al., 2009). Moreover, the morphology influence on the resulting sensing properties is discussed for the particles having relatively large size (from several tens to several hundred $\mathrm{nm}$ ). Therefore, the specific surface area of these materials should be relatively low and the final sensor response is rather determined by intergrain boundaries (Goepel and Schierbaum, 1995).

The organometallic synthesis route developed in our team is a rational way to prepare metal and metal oxide nanoparticles of very low size with a well-controlled monodispersity and morphology (Chaudret, 2005). This method consists in low-temperature decomposition of organometallic precursors in organic solvent in the presence of stabilizing agents such as polymers or various ligands. $\mathrm{ZnO}$ nanostructures of controlled morphology can be also synthesized by this method (Kahn et al., 2005). One of its principal advantages relies in the control of nanoparticle shape and size without drastic change of the synthesis conditions, so different $\mathrm{ZnO}$ nanostructures can be prepared by the same synthetic procedure. As compared to many other methods (Kolodziejczak-Radzimska and Jesionowski, 2014), where high temperatures and/or pressure are required, the preparation of $\mathrm{ZnO}$ nanostructures is performed at room temperature and at atmospheric pressure. Therefore, this unique one-pot reaction does not require any special apparatus, leading to simplest and less energy consuming means for preparation of $\mathrm{ZnO}$ nanoparticles. In this paper, the synthesis of $\mathrm{ZnO}$ nanostructures with different morphologies, from welldefined isotropic nanoparticles to high aspect-ratio nanorods, and the study of their response to three different reducing gases, i.e. $\mathrm{CO}, \mathrm{C}_{3} \mathrm{H}_{8}$ and $\mathrm{NH}_{3}$, are presented. It is therefore possible to compare the 
surface reactivity of preferentially exposed crystalline faces. The role of the nanostructure's morphology on the sensors response and selectivity are discussed.

\section{Experimental Section}

\section{Synthesis of ZnO nanoparticles}

The $\mathrm{ZnO}$ nanostructures of different shapes, i.e. isotropic nanoparticles (NP), cloud-like nanostructures (CL) and high aspect-ratio nanorods (NR), have been synthesized according to an adapted method from our previous work (Kahn et al. 2005). All nanoparticles have been obtained by the hydrolysis of the same organometallic precursor, namely the dicyclohexylzinc (II) ([ZnCy2], NanoMePS, France, 99\% purity). Octylamine (Sigma Aldrich) is used as stabilizing agent. THF is collected from solvent purification system (Braun MB-SPS-800). Distilled water has been degassed with argon during $30 \mathrm{~min}$ prior to use. All reactions have been performed at room temperature and under argon atmosphere. In order to prepare $\mathrm{ZnO} \mathrm{NP}, 0.25 \mathrm{mmol}$ dicyclohexylzinc (II) precursor and 0.25 mmol octylamine ( 1 molar eq. regarding $\mathrm{Zn}$ ) have been dissolved in $4 \mathrm{~mL}$ of THF. In a second step, 2 $\mathrm{mL}$ of humidified THF ( $1 \mathrm{mmol}$ of $\mathrm{H}_{2} \mathrm{O}, 4$ molar eq. regarding $\mathrm{Zn}$ ) has been added dropwise to [ $\mathrm{ZnCy}_{2}$ ] solution. The addition of humidified THF in a limpid [ $\left.\mathrm{ZnCy}_{2}\right]$ solution leads rapidly to a yellowish phase. After a few minutes the yellow solution evolves to give rise to a white precipitate. After $16 \mathrm{~h}$ of reaction, the nanoparticles have been separated by centrifugation $\left(1000 \mathrm{rpm}, 5 \mathrm{~min}, 20^{\circ} \mathrm{C}\right)$ and washed 3 times with $5 \mathrm{~mL}$ of acetone (Sigma Aldrich). ZnO CL structures are obtained by following the same procedure but without addition of any surfactant. In order to prepare $\mathrm{ZnO} \mathrm{NR}$, a mixture of $0.25 \mathrm{mmol}$ of dicyclohexylzinc (II) and $0.5 \mathrm{mmol}$ ( 2 molar eq. regarding $\mathrm{Zn}$ ) of pure octylamine have been introduced into a $4 \mathrm{~mL}$ glass flask. The flask has been placed in a flat-bottomed reactor closed with a septum. In a second step, $18 \mu \mathrm{L}$ ( $1 \mathrm{mmol}, 4$ molar eq. regarding $\mathrm{Zn}$ ) of $\mathrm{H}_{2} \mathrm{O}$ has been added to the reactor through the septum with a syringe. After 4 days, the nanorods have been dispersed in THF ( $6 \mathrm{~mL})$. Finally, the nanorods have been separated by centrifugation $\left(1000 \mathrm{rpm}, 5 \mathrm{~min}, 20^{\circ} \mathrm{C}\right)$ and washed 3 times with $5 \mathrm{~mL}$ of acetone.

\section{$\mathrm{ZnO}$ characterization}

Transmission Electron Microscopy (TEM), High Resolution Transmission Microscopy (HRTEM) and Scanning Electron Microscopy Field Effect Gun (SEM-FEG) experiments have been carried out respectively on a JEOL JEM 1011, JEOL JEM 2100F and on a JEOL JSM 6700F, at the "Service Commun de Microscopie de L'Université Toulouse III Paul Sabatier”. TEM, HRTEM and SEM-FEG images have been used to determine the morphology, particle size, and size distribution. The latter is determined from more than 200 particles of each sample. The obtained $\mathrm{ZnO}$ nanoparticles have been studied by X-ray powder diffraction (XRD) on a SEIFERT XRD 300 TT diffractometer operated under $\mathrm{Cu} \mathrm{K} \alpha$ radiation, fitted with a diffracted-beam graphite monochromator. The data have been collected in the $2 \theta$ configuration between 10 and $70^{\circ}$. Average crystallite size values (FWHM) were calculated by Debye-Scherrer formula for (100), (002) and (101) peaks with PANalytical HighScore Plus program. The specific surface area has been determined by the Brunauer-Emmett-Teller (BET) method at $77 \mathrm{~K}$ using an ASAP2020 Physisorption Analyzer. Thermogravimetric (TGA) measurements have been performed in order to evaluate the efficiency of the washing steps of the as-prepared $\mathrm{ZnO}$ colloidal solutions (Setaram 92-16.18 Thermobalance). The measure of weight loss upon heating of previously 
washed samples is attributed to the residual ligands elimination (ramp $10^{\circ} \mathrm{C} / \mathrm{min}$, temperature step between 25 and $550^{\circ} \mathrm{C}$, air).

\section{ZnO sensing films deposition and conductivity measurements}

The as-prepared and washed $\mathrm{ZnO}$ nanoparticles have been dispersed in ethanol (Sigma Aldrich) with a concentration of $0.5 \%$ wt. of $\mathrm{ZnO}$. $\mathrm{ZnO}$ sensing layers have been drop deposited on a miniaturized micromachined silicon substrate by a generic ink-jet method (Autodrop AD system, Microdrop AG). The silicon platform (Fig. 1) has been developed by the Laboratoire d'Analyse et d'Architecture des Systèmes, LAAS-CNRS, MICA team. The die size is $2 \times 2 \mathrm{~mm}$, and presents a $1.4 \mu \mathrm{m}$ thick dielectric membrane $\left(\mathrm{SiN}_{\mathrm{x}} / \mathrm{SiO}_{2}\right)$ designed for the thermal insulation of the heated zone. The platinum heater with a spiral shape, is buried between the bottom dielectric membrane and a top layer of silicon dioxide. This heater structure stands a temperature up to $700^{\circ} \mathrm{C}$, and the power consumption is as low as of $55 \mathrm{~mW}$ at an operating temperature of $500^{\circ} \mathrm{C}$. The platinum interdigitated electrodes for the resistance measure of the sensitive layer are deposited in a final step on top of the $\mathrm{SiO}_{2}$ insulating layer. A distance of $10 \mu \mathrm{m}$ between each electrode pole provides a reliable contact with sensing layers and offers the access to highly resistive materials measurements (Menini et al., 2008).

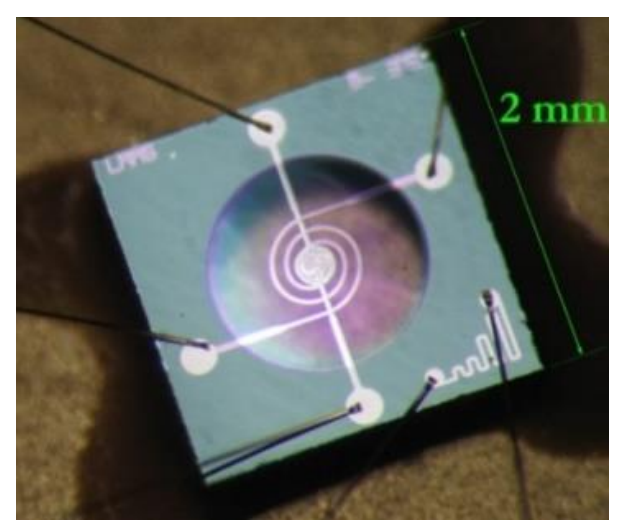

Fig. 1 Image of the gas sensor silicon platform (LAAS).

Gas tests have been performed using a PC controlled setup composed of different gas bottles connected to mass flow controllers (QualiFlow) driven by an Agilent Data Acquisition/Switch Unit 34970A. Sensors are placed in a measurement cell equipped with humidity and temperature sensors. The integrated heaters are controlled by a HP6642A system. A National Instruments 6035E electronic card establishes the connection between the computing unit and the measurement cell. Freshly prepared sensors are initially prepared in ambient air by in situ annealing of the sensitive layer up to $550^{\circ} \mathrm{C}$. The sensors resistance is then stabilized by an operation at $500^{\circ} \mathrm{C}$ under a continuous flow (1L. $\mathrm{min}^{-1}$ ) of synthetic air during several hours. Finally, the sensors are exposed to $100 \mathrm{ppm}$ and $490 \mathrm{ppm} \mathrm{CO}, 100$ and $400 \mathrm{ppm} \mathrm{C}_{3} \mathrm{H}_{8}$, and $19 \mathrm{ppm} \mathrm{NH}_{3}$ at operating temperatures of $500^{\circ} \mathrm{C}, 400^{\circ} \mathrm{C}$, and $340^{\circ} \mathrm{C}$. The relative humidity (RH) is kept constant at $50 \%$, and the total gas flow rate is $1 \mathrm{~L} . \mathrm{min}^{-1}$. Results reported here have been performed by using at least 3 sensors of each category, i.e. $\mathrm{ZnO} \mathrm{NP}, \mathrm{CL}$ and NR.

\section{Results and Discussion}

\section{Characterization of $\mathrm{ZnO}$ nanoparticles}


The TEM images of the $\mathrm{ZnO}$ nanoparticles with different morphology are presented on Fig. 2. The controlled hydrolysis of the dicyclohexylzinc (II) precursor in THF solution without any ligands leads to the formation of cloud-like ( $\mathrm{ZnO} \mathrm{CL}$ ) structures $(30-100 \mathrm{~nm}$ ) assembled from agglomerated $\mathrm{ZnO}$ nanoparticles (2-3 nm) (Fig. 2a). Isotropic nanoparticles (ZnO NP) with an average diameter of 5.1 \pm 1.1 $\mathrm{nm}$ (Fig. 2b) have been obtained by the controlled hydrolysis of [ $\left.\mathrm{ZnCy}_{2}\right]$ in THF solution and in the presence of octylamine. Well-defined nanorods ( $\mathrm{ZnO} \mathrm{NR}$ ) with an average diameter of $5.3 \pm 1.0 \mathrm{~nm}$ and a length of $21 \pm 6 \mathrm{~nm}$ (Fig. 2c) are formed in the case of a [ $\left.\mathrm{ZnCy}_{2}\right]$ hydrolysis in pure octylamine medium. The mean diameter of the particles is evaluated by fitting of the histogram with a Gaussian curve. The first value corresponds to the center of the peak whereas the second one corresponds to twice the standard deviation of the Gaussian distribution or approximately 0.849 the width of the peak at half-height.

HRTEM images of NR and NP structures are presented on Fig. S1a and 1b. On S1a picture, two NP particles are laying on their basal (0001) face, whereas the third one is placed laterally. Figure S1b shows several $\mathrm{ZnO}$ NB laying along their lateral faces. All particles are monocrystalline.
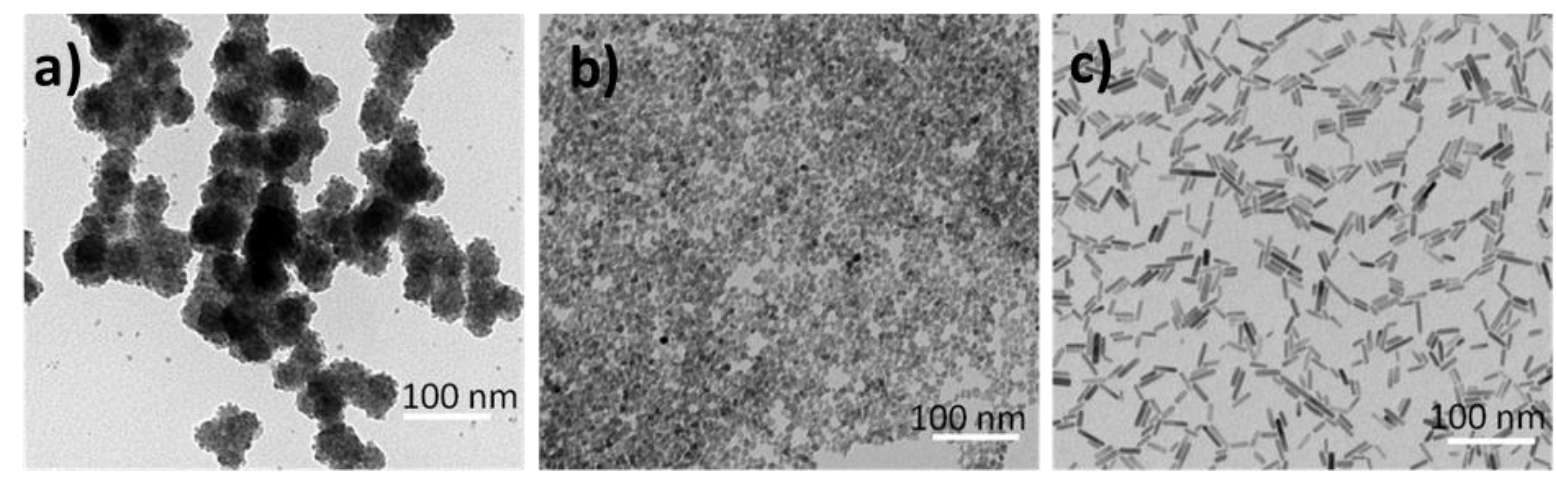

Fig. 2 TEM images of $\mathrm{ZnO}$ nanoparticles with different morphology:

(a) $\mathrm{ZnO} \mathrm{CL}$, (b) $\mathrm{ZnO} \mathrm{NP,} \mathrm{(c)} \mathrm{ZnO} \mathrm{NR}$.

The X-rays diffractograms of as-prepared and washed with acetone $\mathrm{ZnO}$ nanostructures are presented on Fig. 3. All the samples contain only hexagonal zincite phase (JCPDS 26-1451). A sharp and high intensity diffraction peak corresponding to $(002)$ plane $\left(2 \theta=34.6^{\circ}\right)$ is observed on the XRD spectrum of $\mathrm{ZnO} N R$. These results are characteristic of the growth of the crystal along the $c$ crystallographic axe of the Wurzite structure. In contrast and as expected, this is not observed for $\mathrm{ZnO}$ NP or ZnO CL. The average crystallite size values calculated by the Debye-Sherrer formula are respectively $3 \mathrm{~nm}$ and $7 \mathrm{~nm}$ for $\mathrm{ZnO} \mathrm{CL}$ and $\mathrm{ZnO} \mathrm{NP}$. In the case of $\mathrm{ZnO} \mathrm{NR}$ the crystallite size is around $5 \mathrm{~nm}$ for the transversal axis and $26 \mathrm{~nm}$ for the longitudinal one. These results confirm the growth of $\mathrm{ZnO}$ nanorods along of preferential c-axis of the zincite phase and are in accordance with previous data (Chaudret et al., 2005).

According to the thermogravimetric (TGA) analysis, the washed sample of $\mathrm{ZnO} \mathrm{NP}$ contains a residual level of c.a. 0.1 eq. octylamine, i.e. $10 \%$ molar (Fig. S2a). Surprisingly, in the case of ZnO NR the washing with acetone is less effective, since the sample still contains 0.2 eq. of octylamine after the same washing procedure (Fig. S2b). These results can be explained by stronger Van-der-Waals (hydrophobic) interactions between alkyl chains of amines and $\mathrm{ZnO}$ nanorods as compared to the isotropic nanoparticles. To support this hypothesis, we have previously demonstrated that the amine ligands are preferentially coordinated on the lateral faces of $\mathrm{ZnO}$ nanocrystals (Coppel et al., 2012). Anyway, this slightly higher level of residual amine coordinated to $\mathrm{ZnO} \mathrm{NR}$ does not impact the sensor performance since the in-situ heating up to $550^{\circ} \mathrm{C}$ is efficient enough to fully remove all organic residues from the sensitive layer. 


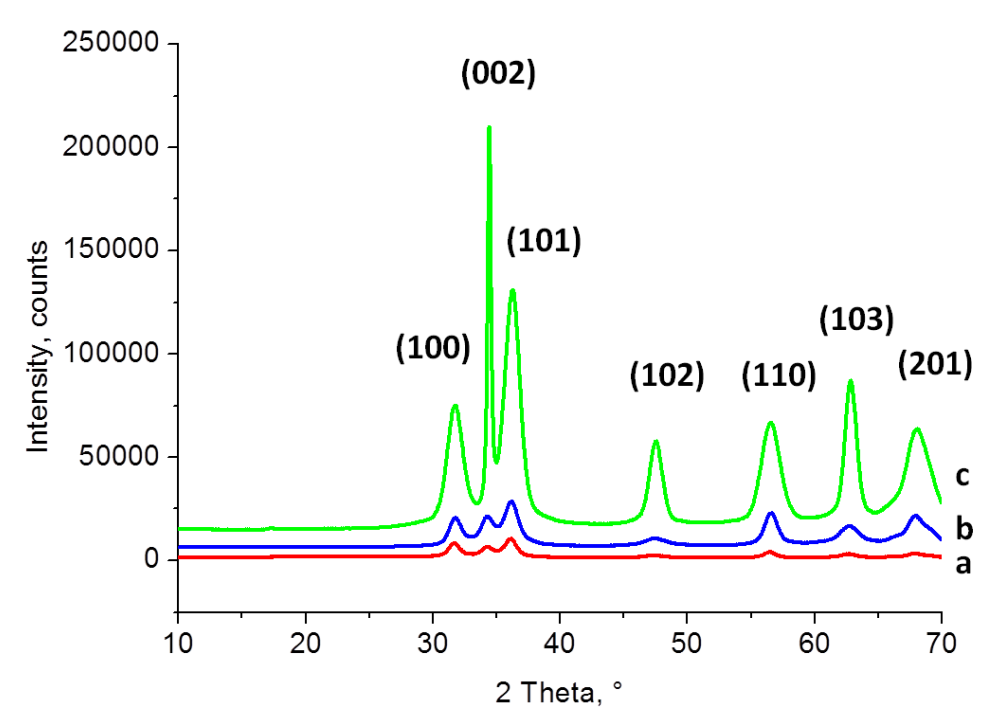

Fig. 3 X-rays diffractograms of $\mathrm{ZnO}$ nanoparticles with different morphology:

(a) $\mathrm{ZnO} \mathrm{CL}$, (b) $\mathrm{ZnO} \mathrm{NP,} \mathrm{(c)} \mathrm{ZnO} \mathrm{NR}$.

\section{Properties of $\mathrm{ZnO}$ layers}

The $\mathrm{ZnO}$ nanoparticles have been deposited as gas sensitive layers on silicon chips by an inkjet method. After deposition, the layers have been in situ annealed by operating the integrated Pt heater up to $550^{\circ} \mathrm{C}$. The annealing and stabilization temperature profile is presented in Fig. 4. The long intermediate steps performed at low temperature $\left(150^{\circ}-350^{\circ} \mathrm{C}\right)$ allow the slow removal of solvent and ligand traces from the sensitive layers. High quality layers with $\mathrm{ZnO}$ thickness of 5-10 $\mu \mathrm{m}$ without large cracks or delamination are obtained (Fig. 5a). The microstructure of the layers was investigated by SEMFEG observations. It is noteworthy that, the morphology of $\mathrm{ZnO}$ nanoparticles is retained on the silicon platform even after in-situ thermal treatment up to $550^{\circ} \mathrm{C}$ (Fig. $5 \mathrm{~b}, \mathrm{c}, \mathrm{d}$ ).

Gas sensing properties towards various reducing gases, namely $100 \mathrm{ppm}$ and $490 \mathrm{ppm} \mathrm{CO}, 100$ and $400 \mathrm{ppm} \mathrm{C}_{3} \mathrm{H}_{8}$, and $19 \mathrm{ppm} \mathrm{NH}_{3}$ have been studied in the temperature range of $340^{\circ}-500^{\circ} \mathrm{C}$ and relative humidity (RH) of 50\%. These concentrations have been chosen in a range which is of interest for usual air quality standards (OSHA Permissible Exposure Limits). The representative results of the temperature effect on the sensors response are shown on Fig. 6. The electrical resistance of the different $\mathrm{ZnO}$ sensitive layers decreases with the operating temperature and reaches its minimum value of few $\mathrm{MOhms}$ at $500^{\circ} \mathrm{C}$. Moreover, at this temperature, the resistance of the different sensors decreases in the following order: $\mathrm{ZnO} \mathrm{NR}>\mathrm{ZnO} \mathrm{NP}>\mathrm{ZnO} \mathrm{CL}$. The resistance decreases also in the presence of reducing gases. This is a characteristic behavior of the n-type semiconductor sensors. It is noteworthy that, the sensors have shown fast and reversible responses to tested gases. However, no performance tests have been carried out below $340^{\circ} \mathrm{C}$ because of the too slow reaction times as well as too high sensors resistance at low temperature. Resistance is measured before and after sensors exposure to reducing gas mixture and the normalized response (\%) to each gas is calculated as $\mathrm{Rn}(\%)=\left(\mathrm{R}_{\mathrm{air}}-\mathrm{R}_{\mathrm{gas}}\right) / \mathrm{R}_{\mathrm{air}} * 100$. Typical values of the normalized sensors response to reducing gases at different temperature are displayed on Fig. 7. In order to quantitatively estimate the selectivity of gas detection, the selectivity coefficient $\left(\mathrm{K}_{\text {sel }}\right)$, which 
corresponds to the ratio of the sensors normalized response to different gases $\left(K_{\text {sel }}=R_{\text {gas } 1} / R_{\text {gas } 2}\right)$, has been also calculated. We assume that a $K_{\text {sel }}$ coefficient with a value higher than 2 corresponds to a selective response to a given gas.

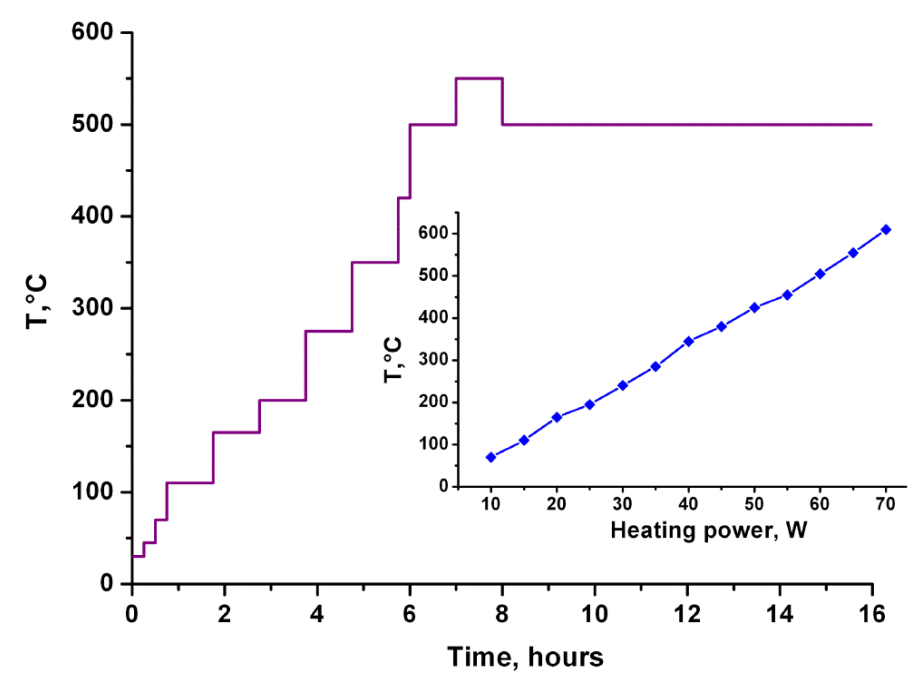

Fig. 4 Temperature profile of the annealing protocol of $\mathrm{ZnO}$ sensing layers (insert: relation between heating power and sensor temperature).
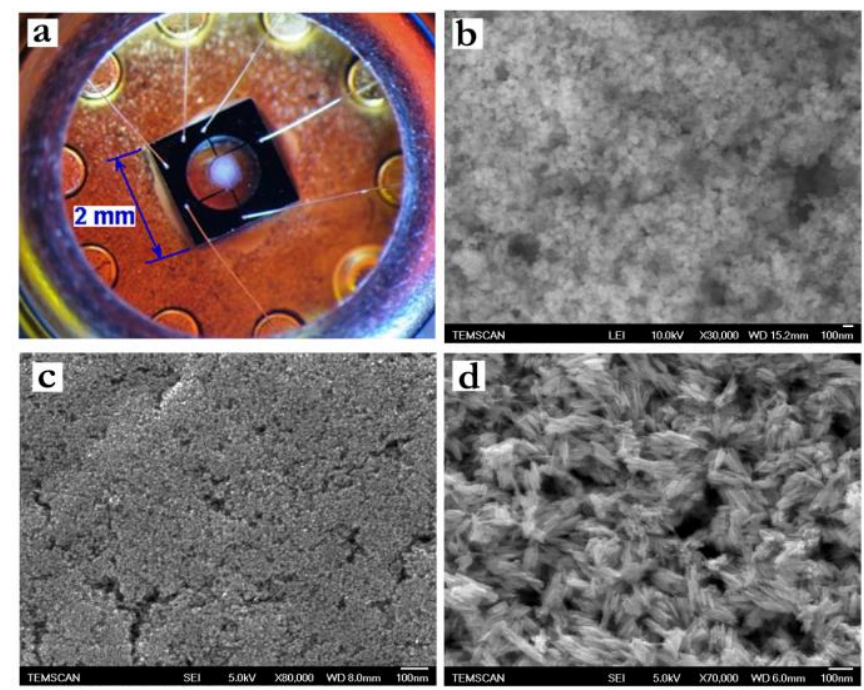

Fig. 5 (a) Picture of a sensor covered with $\mathrm{ZnO}$ sensitive layer and SEM-FEG images of (b) $\mathrm{ZnO} \mathrm{CL}$, (c) $\mathrm{ZnO} \mathrm{NP}$, and (d) $\mathrm{ZnO} \mathrm{NR}$ sensitive layers after in-situ thermal treatment up to $550^{\circ} \mathrm{C}$. 

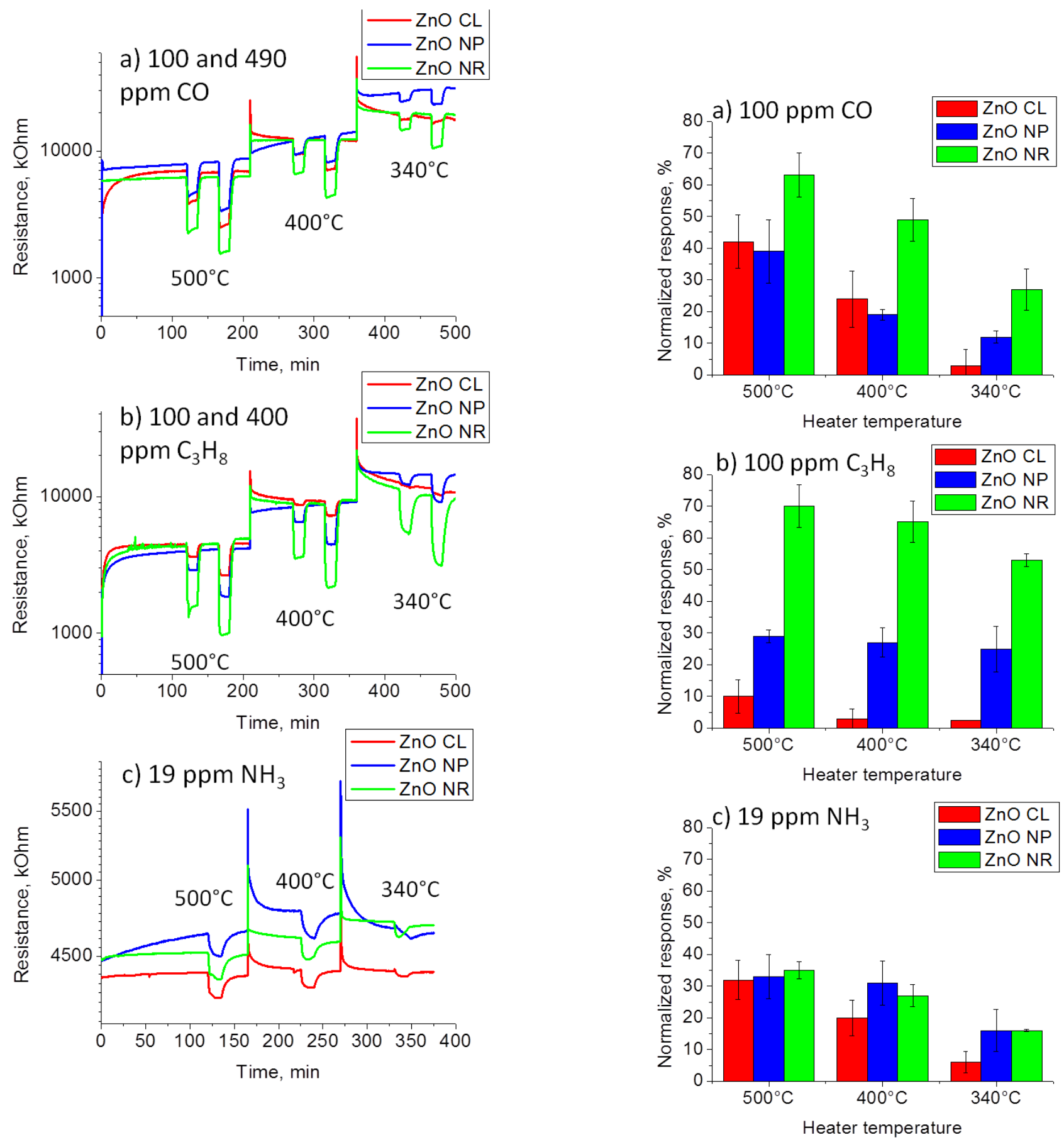

Fig. 6 Typical sensors response obtained for $\mathrm{ZnO}$ Fig. 7 Normalized responses obtained for $\mathrm{ZnO}$ $\mathrm{CL}, \mathrm{NP}$, and NR at different operating temperatures $\left(500,400\right.$ and $\left.340^{\circ} \mathrm{C}\right)$ and at relative humidity of $50 \%$ (Y scale in log plot). (a) 100 and 490 ppm CO, (b) 100 and 400 ppm C $_{3} \mathrm{H}_{8}$, (c) 19 ppm $\mathrm{NH}_{3}$. CL, NP and NR at different operating temperatures $\left(500,400\right.$ and $\left.340^{\circ} \mathrm{C}\right)$ and at relative humidity of 50\%. (a) 100 ppm CO, (b) 100 ppm $\mathrm{C}_{3} \mathrm{H}_{8}$, (c) 19 ppm NH .

Undeniably, the most important result is that the nanostructure of $\mathrm{ZnO}$ layers influences the sensors response (Fig. 6 and Fig. 7). The ZnO NR sensors show the highest sensitivity to all tested gases. The 


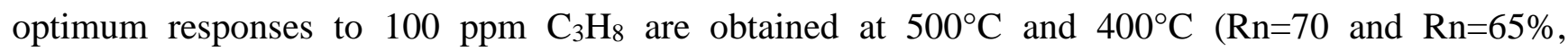
respectively). However, the response towards this gas remains high even at lower operating temperature $\left(\mathrm{Rn}=53 \%\right.$ at $\left.340^{\circ} \mathrm{C}\right)$. The highest response to $100 \mathrm{ppm} \mathrm{CO}$ has also been achieved with $\mathrm{ZnO}$ NR operated at $500^{\circ} \mathrm{C}\left(\mathrm{R}_{\mathrm{n}}=63 \%\right)$. The response towards this gas decreases slightly with temperature diminution $\left(\mathrm{R}_{\mathrm{n}}=49 \%\right.$ at $400^{\circ} \mathrm{C}$ and $\mathrm{Rn}=27 \%$ at $\left.340^{\circ} \mathrm{C}\right)$. The best response to $19 \mathrm{ppm} \mathrm{NH}_{3}$ has also been obtained with $\mathrm{ZnO} \mathrm{NR}\left(\mathrm{R}_{\mathrm{n}}=35 \%\right.$ at $\left.500^{\circ} \mathrm{C}\right)$, but the other sensors categories are very close to this level $\left(\mathrm{R}_{\mathrm{n}}=33 \%\right.$ and $32 \%$ for $\mathrm{ZnO} \mathrm{NP}$ and $\mathrm{ZnO} \mathrm{CL}$, respectively). The response towards $\mathrm{NH}_{3}$ also decreases with temperature lowering $\left(\mathrm{R}_{\mathrm{n}}=27 \%\right.$ at $400^{\circ} \mathrm{C}$ and $\mathrm{Rn}=16 \%$ at $\left.340^{\circ} \mathrm{C}\right)$. These results suggest that the $\mathrm{ZnO} \mathrm{NR}$ sensors show good selectivity for $\mathrm{C}_{3} \mathrm{H}_{8}$ relatively to $\mathrm{NH}_{3}$ at all tested temperatures. Indeed, $\mathrm{K}_{\text {sel }} \mathrm{C} 3 \mathrm{H} 8 / \mathrm{NH} 3$ at 500,400 and $340^{\circ} \mathrm{C}$ is equal to $2.0,2.4$ and 3.3, respectively. Additionally, at the lowest temperature of $340^{\circ} \mathrm{C}$ the sensors exhibit a rather satisfying selectivity for $\mathrm{C}_{3} \mathrm{H}_{8}$ versus $\mathrm{CO}\left(\mathrm{K}_{\mathrm{sel}} \mathrm{C} 3 \mathrm{H} 8 / \mathrm{CO}=2.0\right)$. Consequently, the $\mathrm{ZnO}$ NR sensors can be used for sensitive and selective $\mathrm{C}_{3} \mathrm{H}_{8}$ detection in the presence $\mathrm{CO}$ and $\mathrm{NH}_{3}$ if they are operated at $340^{\circ} \mathrm{C}$.

The $\mathbf{Z n O}$ NP sensors show the same response to $100 \mathrm{ppm} \mathrm{C}_{3} \mathrm{H}_{8}$ whatever the operating temperature, i.e. the response of the sensors only slightly varies from $\mathrm{R}_{\mathrm{n}}=29 \%$ to $\mathrm{Rn}=25 \%$ when decreasing the temperature from 500 to $340^{\circ} \mathrm{C}$. The response to $100 \mathrm{ppm} \mathrm{CO}$ is much more affected by the operating temperature since the response drops from $\mathrm{R}_{n}=39 \%$ at $500^{\circ} \mathrm{C}$ to only $\mathrm{R}_{\mathrm{n}}=12 \%$ at $340^{\circ} \mathrm{C}$. Therefore, the $\mathrm{ZnO}$ NP sensors show slight improvement of selectivity between $\mathrm{C}_{3} \mathrm{H}_{8}$ and $\mathrm{CO}$ by simply varying the operating temperature $\left(\mathrm{K}_{\mathrm{sel}} \mathrm{C} 3 \mathrm{H} 8 / \mathrm{CO}=0.7\right.$ at $500^{\circ} \mathrm{C}$ and 2.1 at $\left.340^{\circ} \mathrm{C}\right)$. The response to $19 \mathrm{ppm} \mathrm{NH}$ is at a similar level as compared to the $\mathrm{ZnO} \mathrm{NR}$ sensors. Consequently, the selectivity for $\mathrm{C}_{3} \mathrm{H}_{8}$ or $\mathrm{CO}$ gases relatively to $\mathrm{NH}_{3}$ is always poor with the ZnO NP sensors. No significant response variations are obtained between $\mathrm{NH}_{3}$ and the other investigated gases within the range of operating temperature.

From all tested morphologies, ZnO CL category shows very low response to $100 \mathrm{ppm} \mathrm{C}_{3} \mathrm{H}_{8}$, which varies from $\mathrm{Rn}=10 \%$ at $500^{\circ} \mathrm{C}$ to $\mathrm{Rn}=2.5 \%$ at $340^{\circ} \mathrm{C}$. The response to $100 \mathrm{ppm} \mathrm{CO}$ is comparable to $\mathrm{ZnO} N P$ category and varies from $\mathrm{R}_{\mathrm{n}}=42 \%$ at $500^{\circ} \mathrm{C}$ to $\mathrm{R}_{\mathrm{n}}=3 \%$ at $340^{\circ} \mathrm{C}$. The response to $19 \mathrm{ppm} \mathrm{NH}_{3}$ is at a similar level as compared to $\mathrm{ZnO} \mathrm{NP}$ and NR sensors. Thus, the $\mathrm{ZnO} \mathrm{CL}$ sensors have high selectivity for $\mathrm{NH}_{3}$ or $\mathrm{CO}$ relatively to $\mathrm{C}_{3} \mathrm{H}_{8}$. Indeed, $\mathrm{K}_{\text {sel }} \mathrm{NH}_{3} / \mathrm{C} 3 \mathrm{H} 8$ at 500,400 and $340^{\circ} \mathrm{C}$ is equal to 3.2, 6.7, and 2.4, respectively. In addition, $\mathrm{K}_{\mathrm{sel} \mathrm{CO} / \mathrm{C} 3 \mathrm{H} 8}$ is equal to 4.2, 7.0, and 1.2, respectively. Therefore, the $\mathrm{ZnO} C \mathrm{C}$ sensors can be used for selective detection of $\mathrm{NH}_{3}$ or $\mathrm{CO}$ in the presence of $\mathrm{C}_{3} \mathrm{H}_{8}$, especially if the sensors are operated at the mean temperature of $400^{\circ} \mathrm{C}$.

In summary, the $\mathrm{ZnO}$ NR sensors present the best sensitivity to $100 \mathrm{ppm} \mathrm{CO}$ or $\mathrm{C}_{3} \mathrm{H}_{8}$. Additionally, these sensors exhibit good selectivity towards $\mathrm{C}_{3} \mathrm{H}_{8}$ relatively to $\mathrm{CO}$ and $\mathrm{NH}_{3}$ when operated at $340^{\circ} \mathrm{C}$. The responses of $\mathrm{ZnO}$ NP sensors lay at a mean level. They show a CO sensitivity similar to the level obtained with $\mathrm{ZnO} C L$, but they display a higher response to $\mathrm{C}_{3} \mathrm{H}_{8}$. From all tested morphologies, $\mathrm{ZnO}$ $\mathrm{NP}$ exhibit the weakest selectivity between investigated gases. Moreover, the $\mathrm{ZnO}$ CL category presents the best selectivity for $\mathrm{NH}_{3}$ or $\mathrm{CO}$ versus $\mathrm{C}_{3} \mathrm{H}_{8}$ at an operating temperature of $400^{\circ} \mathrm{C}$. The specific surface area of these different $\mathrm{ZnO}$ nanostructures has been measured by the BET method. $\mathrm{ZnO}$ NR presents a lower $\left(31.6 \mathrm{~m}^{2} \cdot \mathrm{g}^{-1}\right)$, specific surface than ZnO NP $\left(47.9 \mathrm{~m}^{2} \cdot \mathrm{g}^{-1}\right)$ or CL $\left(41.2 \mathrm{~m}^{2} \cdot \mathrm{g}^{-1}\right)$. Therefore, high sensitivity of the $\mathrm{ZnO} \mathrm{NR}$ is not related to this parameter and the differences in sensors performance must be correlated to the exposed crystalline faces and their reactivity to the target molecules.

The prismatic faces $((10 \overline{1} 0)$ and $(11 \overline{2} 0))$ of $\mathrm{ZnO} \mathrm{NR}$ crystal, which are terminated by both $\mathrm{O}$ and $\mathrm{Zn}$ atoms, geometrically represent at least $90 \%$ of the total surface of the crystal. In this study, the highest sensor response to $\mathrm{CO}$ is obtained with $\mathrm{ZnO}$ NR morphology (Fig. 7). This result suggests a higher adsorption affinity of $\mathrm{CO}$ molecules to prismatic face of $\mathrm{ZnO}$ nanocrystals (Scarano et al. 1992). Since $\mathrm{CO}$ reaction on MOS sensors surface always rely on chemisorbed $\mathrm{O}^{-}$oxygen species (Goepel and 
Schierbaum, 1995), this suggests that the lateral faces of ZnO NR present a higher ratio of chemisorbed oxygen than the basal surfaces.

In the case of $\mathrm{ZnO} \mathrm{NP}$ and $\mathrm{CL}$, where lateral and basal faces are equivalently exposed, the response to $\mathrm{CO}$ gas is much lower than for $\mathrm{ZnO}$ NR. From this result it can be hypothesized that the higher ratio of basal faces are less favorable to $\mathrm{CO}$ adsorption compared to lateral faces. An experimental answer to this question could be resolved by the preparation of new $\mathrm{ZnO}$ nanostructures displaying extended areas of basal planes and a minimum c- axis length.

As shown on Fig. 7, sensors based on $\mathrm{ZnO}$ NP and especially on $\mathrm{ZnO}$ NR are more sensitive to 100 ppm $\mathrm{C}_{3} \mathrm{H}_{8}$ (respectively $\mathrm{R}_{\mathrm{n}}=39 \%$ and $70 \%$ at $500^{\circ} \mathrm{C}$ ) than $\mathrm{ZnO} \mathrm{CL}\left(\mathrm{R}_{\mathrm{n}}=10 \%\right.$ at $\left.500^{\circ} \mathrm{C}\right)$. Therefore, we conclude that both basal and especially lateral faces are involved in the reactivity of $\mathrm{ZnO}$ to $\mathrm{C}_{3} \mathrm{H}_{8}$. It can be supposed that the poor cristallinity of CL sensors type (Fig. 3) conducts to very unfavorable adsorption conditions for propane (Katoch et al., 2013).

The sensors responses to $19 \mathrm{ppm} \mathrm{NH}_{3}$ at $500^{\circ} \mathrm{C}$ are rather similar for all $\mathrm{ZnO}$ categories. However the temperature influence is more pronounced for the $\mathrm{ZnO} \mathrm{CL}$ sensors than for the others morphologies. At $340^{\circ} \mathrm{C}$ the $\mathrm{ZnO} \mathrm{CL}$ sensors have lost almost all their reactivity to all gases, whereas the more crystalline samples (NR and NP) still retain significant levels of responses $\left(\mathrm{R}_{\mathrm{n}}>10 \%\right)$. Contrarily to $\mathrm{C}_{3} \mathrm{H}_{8}, \mathrm{NH}_{3}$ is a polar molecule and a strong Lewis base which preferentially adsorbs at metal-ionic sites (Lewis acid sites) on metal-oxide surfaces (Ozawa et al., 2009). A higher ratio of Lewis acid sites ( $\mathrm{Zn}$ atoms) should be assumed in the case of $\mathrm{ZnO} \mathrm{CL}$ at high temperature $\left(500^{\circ} \mathrm{C}\right)$. Finally, the sensitivity of the $\mathrm{ZnO}$ sensors to reducing gases can be tuned by the use of nanoparticles with very distinct morphology. Taking advantage of the temperature-dependent selectivity of each sensor, and with the help of a mathematical treatment of their signals (such as Principal Component Analysis), a sensors system dedicated to the recognition of gaseous components in a complex mixture could be built with a set of different morphology $\mathrm{ZnO}$ sensitive layers.

\section{Conclusions}

In this paper, the organometallic synthesis route has been employed to yield $\mathrm{ZnO}$ nanoparticles with very distinct morphologies. Their response to three different reducing gases, namely, $\mathrm{CO}, \mathrm{C}_{3} \mathrm{H}_{8}$ and $\mathrm{NH}_{3}$ has been measured and compared. It has clearly been established that the morphology of $\mathrm{ZnO}$ nanostructures significantly influences the sensors gases responses and therefore offers a possible selectivity improvement way for gas sensing device. The sensors based on $\mathrm{ZnO}$ CL structures present the highest selectivity for $\mathrm{CO}$ or $\mathrm{NH}_{3}$ relatively to $\mathrm{C}_{3} \mathrm{H}_{8}$ when operating at $400^{\circ} \mathrm{C}$. $\mathrm{ZnO} \mathrm{NR}$ sensors display a high response to all tested gases with an optimum selectivity for $\mathrm{C}_{3} \mathrm{H}_{8}$ comparably to $\mathrm{CO}$ and $\mathrm{NH}_{3}$ when operating at $340^{\circ} \mathrm{C}$. $\mathrm{ZnO}$ NP layers present a mean response level to all tested gases. However, this category presents the best stability of the response for $\mathrm{C}_{3} \mathrm{H}_{8}$ between 340 to $500^{\circ} \mathrm{C}$. The influence of $\mathrm{ZnO}$ morphology on sensing behavior is explained by the variation of the nature of the crystalline faces of the $\mathrm{ZnO}$ structure exposed to the gas phase. In conclusion, this study is the first step dedicated to the preparation of a multisensor system based on chemoresistive layers with a single chemical composition, but with specific morphologies and different operating temperatures. New experiments are underway in order to evaluate the response and selectivity of the various $\mathrm{ZnO}$ sensing layers with mixtures of reducing gases. 


\section{Acknowledgments}

This work was supported by the Région Midi Pyrénées, and PRES Université de Toulouse in the frame of the NELI (Nez Electronique Intégré) project. We also thank CNRS, Université Toulouse III Paul Sabatier and Alpha MOS SA for support.

\section{Author Contributions}

All authors contributed equally to the reported research and writing of the paper.

\section{Conflicts of Interest}

The authors declare no conflict of interest.

\section{References}

Bai, S.; Liu, X.; Li, D.; Chen, S.; Luo, R.; Chen, A. Synthesis of ZnO nanorods and its application in $\mathrm{NO}_{2}$ sensors. Sens. Actuat. B 2011, 153(1), 110-116.

Benkstein, K. D.; Raman, B.; Lahr, D. L.; Bonevich, J. E.; Semancik, S. Inducing analytical orthogonality in tungsten oxide-based microsensors using materials structure and dynamic temperature control. Sens. Actuat. B 2009, B137 (1), 48-55.

Chand Singh, R., Singh, O., Pal Singh, M., Singh Chandi, P. Synthesis of zinc oxide nanorods and nanoparticles by chemical route and their comparative study as ethanol sensors. Sens. Actuat. B 2008, (135), 352-357.

Chaudret, B. Organometallic approach to nanoparticles synthesis and self-organization. C. R. Physique 2005, 6(1), 117-131.

Chen, D.; Hou, X.; Li, T.; Fan, D.; Wang, H.; Li, X.; Xu, H.; Lu, H.; Zhang, R.; Sun, J. Effects of morphologies on acetone-sensing properties of tungsten trioxide nanocrystals. Sens. Actuat. B 2011, 153(2), 373-381.

Cobden, P. D., Nieuwenhuys, B. E., Gorodetskii, V.V. Adsorption of some small molecules on a Pd field emitter. Appl. Catal. A 1999, 188(1-2), 69-77.

Coppel, Y.; Spataro, G.; Pagès, C., Chaudret, B., Maisonnat, A.; Kahn, M. L. Full characterization of colloidal solutions of long-alkyl-chain-amine-stabilized $\mathrm{ZnO}$ nanoparticles by NMR spectroscopy: Surface state, equilibria, and affinity. Chem. Eur. J. 2012, 18(17), 5384-5393.

Geng, B.; Fang, C.; Zhan, F.; Yu, N. Synthesis of polyhedral $\mathrm{ZnSnO}_{3}$ microcrystals with controlled exposed facets and their selective gas-sensing properties. Small 2008, 4(9), 1337-1343.

Goepel, W.; Schierbaum, K. D. $\mathrm{SnO}_{2}$ sensors: current status and future prospects. Sens. Actuat. B 1995, 26(1-3), 1-12.

Gupta, S.K.; Joshi, A.; Kaur, M. Development of gas sensors using ZnO nanostructures. J. Chem. Soc. 2010, 122(1), 57-62.

Heilig, A.; Weimar, U.; Schweizer-Berberich, M.; Gardner, J. W.; Gopel, W. Gas identification by modulating temperatures of $\mathrm{SnO}_{2}$-based thick film sensors. Sensors and Actuators B 1997, 43(1-3), 4551. Kahn, M.L.; Collière V., Senocq, F.; Maisonnat, A.; Chaudret, B. Size- and shape-control of crystalline zinc oxide nanoparticles: a new organometallic synthetic method. Adv. Funct. Mater. 2005, 15(3), 458-468.

Katoch, A., Sun, G.-J., Choi, S.-W., Byun, J.-H. Kim, S. S. Competitive influence of grain size and crystallinity on gas sensing performances of ZnO nanofibers, Sens. Actuat. B 2013, 185, 411-416.

Kolodziejczak-Radzimska, A.; Jesionowski, T. ZnO Oxide-from synthesis to application: a review. Materials 2014, 7, 2833-2881.

Le, V. T.; Le, T. N. L.; Nguyen, V. H. Comparative study of gas sensor performance of $\mathrm{SnO}_{2}$ nanowires and their hierarchical nanostructures. Sens. Actuat. B 2010, 150(1), 112-119. 
Liao, F.; Huang, Y.; Ge, J.; Zheng, W.; Tedsree, K.; Collier, P.; Hong, X. Morphology-dependent interactions of $\mathrm{ZnO}$ with $\mathrm{Cu}$ nanoparticles at the materials' interface in selective hydrogenation of $\mathrm{CO}_{2}$ to $\mathrm{CH}_{3} \mathrm{OH}$. Angew. Chem., Int. Ed. 2011, 50 (9), 2162-2165.

Liu, X.; Liu, J.; Chang, Z.; Sun, X.; Li, Y. Crystal plane effect of $\mathrm{Fe}_{2} \mathrm{O}_{3}$ with various morphologies on CO catalytic oxidation. Catal. Commun. 2011, 12(6), 530-534.

Menini, Ph.; Chalabi, H.; Yaboue, N. P.; Scheid, E.; Conedera, V.; Salvagnac, L.; Aguir, K. High performances of new microhotplate for gas sensors. Eurosensors XXII, Dresde (Allemagne), Septembre 2008.

OSHA Permissible Exposure Limits (PELs), https://www.osha.gov/dsg/topics/pel/

Ozawa, K.; Hasagawa, T.; Edamoto, K.; Takahashi, K.; Kamada, M. Adsorption state and molecular orientation of ammonia on $\mathrm{ZnO}(1 \overline{010})$ studied by photoelectron spectroscopy and near-Edge X-ray Absorption Fine Structure Spectroscopy. J. Phys. Chem. B 2002, 106(36), 9380-9386.

Rai, P., Kwak, W.-K., Yu, Y.-T. Solvothermal synthesis of ZnO nanostructures and their morphologydependent gas-sensing properties. Appl. Mater. Interfaces 2013, (5), 3026-3032.

Rout, C.S.; Hegde, M.; Govindaraj, A.; Rao, C. N. R. Ammonia sensors based on metal oxide nanostructures. Nanotechnology 2007, 18(20), 205504/1-205504/9.

Ryzhikov, A., Labeau, M.; Gaskov, A. $\mathrm{Al}_{2} \mathrm{O}_{3}(\mathrm{M}=\mathrm{Pt}, \mathrm{Ru})$ catalytic membranes for selective semiconductor gas sensors. Sens. Actuat. B 2005, 109(1), 91-96.

Scarano, D., Spoto, G., Bordiga, S., Zecchina, A. Lateral interactions in CO adlayers on prismatic ZnO faces: a FTIR and HRTEM study. Surf. Sci. 1992, 276, 281-298

Shaalan, N.M.; Yamazaki, T.; Kikuta, T. Influence of morphology and structure geometry on NO2 gassensing characteristics of $\mathrm{SnO}_{2}$ nanostructures synthesized via a thermal evaporation method. Sens. Actuat. B 2011, 153(1), 11-16.

Simon, I.; Barsan, N.; Bauer, M.; Weimar, U. Micromachined metal oxide gas sensors: opportunities to improve sensor performance. Sens. Actuat. B 2001, 73(1), 1-26.

Wang, D.; Kang, Y.; Doan-Nguyen, V.; Chen, J.; Kungas, R.; Wieder, N. L.; Bakhmutsky, K.; Gorte, R. J.; Murray, C. B. Synthesis and oxygen storage capacity of two-dimensional ceria nanocrystals. Angew. Chem., Int. Ed. 2011, 50(19), p. 4378-4381.

Weimar, U.; Goepel, W. Chemical imaging: II. Trends in practical multiparameter sensor systems. Sens. Actuat. B 1998, 52(1-2), 143-161.

Wu, C.; Zhu, X.; OuYang, C.; Xie, Y. Synthesis of Hematite $\left(\alpha-\mathrm{Fe}_{2} \mathrm{O}_{3}\right)$ Nanorods: diameter-size and shape tffects on their applications in magnetism, lithium ion battery, and gas sensors. J. Phys. Chem. B 2006, 110(36), 17806-17812.

Xu, J., Zhang, Y.; Chen, Y.; Xiang, Q.; Pan, Q.; Shi, L. Uniform ZnO nanorods can be used to improve the response of $\mathrm{ZnO}$ gas sensor. Mater. Sci. Eng. B 2008, 150(1), 55-60.

Yamazoe, N.; Kurokawa, Y.; Seiyama, T. Effects of additives on semiconductor gas sensors. Sens. Actuat. 1983, 4(2), 283-289.

Yu, L.; Fan, X.; Qi, L.; Ma, L.; Yan, W. Dependence of morphologies for $\mathrm{SnO}_{2}$ nanostructures on their sensing property. Appl. Surf. Sci. 2011, 257(7), 3140-3144.

Zhang, W.-D.; Zhang, W.-H.; Ma, X.-Y. Tunable ZnO nanostructures for ethanol sensing. J. Mater. Sci. 2009, 44(17), 4677-4682.

Zhao, Q., Shen, Q., Yang, F., Zhao, H., Liu, B., Liang, Q., Wei, A., Yang, H., Liu, S. Direct growth of $\mathrm{ZnO}$ nanodisk networks with an exposed (0001) facet on Au comb-shaped interdigitating electrodes and the enhanced gas-sensing property of polar (0001) surfaces. Sens. Actuat. B 2014, 195, 71-79. 